\title{
Energy-driven scheduling for Digital Video Broadcasting - Satellite Second Generation (DVB-S2)
}

\begin{abstract}
The continuous growth in wireless data traffic results in the increase in total energy consumption of wireless networks. Therefore, energy-efficient solutions are extremely required to minimize the energy consumption over the entire network. In this paper, an energy-driven scheduling algorithm with optimized throughput, termed as Energy Efficiency Fair (EEF) queuing algorithm, is proposed. Based on energy efficiency of each modulation and coding scheme (MODCOD) available in Digital Video Broadcasting - Satellite Second Generation (DVB-S2), the EEF algorithm improves a scheduling mechanism of a two-step scheduler by selecting frames to be transmitted next according to ñenergy efficiencyò policy developed. The EEF is compared with Round Robin (RR) algorithm, and a gain in energy efficiency of $47 \%$ is obtained when different modulation schemes with common code rate are implemented. Furthermore, EEF outperforms RR by $264 \%$ concerning the useful transmitted bits when QPSK modulation scheme with different coding rates is used.
\end{abstract}

Keyword: DVB-S2; Energy-efficient scheduling; Modulation and coding; Spectral efficiency 